\title{
A Study on Environmental Costs in Coal Mining Production in Vietnam
}

\author{
Thi Dieu Thu Nguyen \\ University of Transport Technology, Vietnam \\ Duc Tru Ha, Van Dang Pham \\ Hanoi University of Business and Technology, Vietnam \\ Van Hoa Hoang \\ National Economic University, Vietnam
}

\begin{abstract}
This study is conducted to identify and present environmental costs of mining production in the context of sustainable development (SD) and a lifecycle of coal mining firms. This aim is accompanied by two research questions as (i) What are the environmental costs of mining production in theory and practice in a lifecycle of coal mining firms?; and (ii) What are the key determinants of environmental costs of coal mining production in a lifecycle of coal mining firms? In order to achieve this aim, the process of coal mining production is described from the long-term perspective including projecting, building, operating and liquidation stage of a coal mine. On the basis of process analysis the identification of environmental costs is conducted in a model approach. Environmental costs of mining production are analyzed using international case studies and theoretical and practical assumptions regarding environmental costs management in mining production are formulated. The results show that the environmental costs of mining production are varied in the lifecycle of a coal mine and that they also depend on the geographical location of mining firms. Environmental costs of mining production have to be predicted in a long-term perspective including also post-liquidation costs together with taking into account the sources of their covering and models of financing.
\end{abstract}

Keywords: Coal mining production, mine, lifecycle of a mine, environmental costs.

DOI: $10.7176 /$ RJFA/11-18-09

Publication date:September $30^{\text {th }} 2020$

\section{Introduction}

Extractive industries have an extremely harmful influence on the environment resulting from two main reasons. The first one is the character of their operational activity. The second one is the temporality of the mining firms operations at the particular area. Mining operations interfere with all segments of ecosystems in the case of both kinds of exploitation (underground, open pit or deep-seabed) (Fugiel et al., 2017; Le et al., 2007). They deform the surface, violate the hydro-system and cause water, air and soil pollutions. In addition, their activity generates huge quantities of waste that require appropriate storage and management. All these factors are the serious threats for human health and life, concerning both the mining staff and the members of local and regional communities (Caputa, 2015; Szromek et al., 2011). Furthermore, the negative influence of the mining firms on the environment is perceptible and noticeable not only during the exploitation but also many years after its completion. Meanwhile, fortunately for the mining firms, the temporality of their operating activities - defined and limited by the sufficiency of deposits - allows them to ignore the environmental consequences and to disregard the community's social needs. After exhausting the current deposits, they would move on to find another attractive localization and start exploitation as new partners in new economic, geographical and civilizational conditions. This is not conducive to lasting economic relations and loyalty to the social and business partners (Brzostek \& Michna, 2016; Gorczyńska, 2011).

The above mentioned consequences are unavoidable because they are strictly connected with the mining operational activity. In such unfavorable circumstances, implementing the rules of sustainable development (SD) in the environmental perspective is a difficult and complicated task which requires mental changes, changes in the organizational culture as well as the additional financial inputs (Michalak, 2016; Bąk, 2007). Nevertheless, there are only two ways of making the extractive industries more environmentally friendly; the first one is to close all mining firms and the second one is to try implement the sustainable development rules into their strategies from the first stage of their existence until the end of their lifecycle, considering the extended time of their influence on environment after the coal mines' liquidation (Stevens \& Dixon, 2017).

There are two research questions to be answered as (i) What are the environmental costs of coal mining production in theory and practice in a lifecycle of coal mining firms?; (ii) What are the key determinants of environmental costs of coal mining production in a lifecycle of the coal mining of Vietnam firms?

Taking into account the above arguments and problems, this research is to identify and to present 
environmental costs of coal mining production in the context of sustainable development (SD) and a lifecycle of the coal mining firms. This aim is realized in three aspects as (i) theoretical - through analyzing the stages of the lifecycle of the coal mining firms; (ii) fragmentary - through analyzing the international case studies of environmental costs in mining firms; and (iii) analytical - through analyzing the environmental costs in Vietnam coal mining.

\section{Research methodology}

Research methodology is fitted to each of the mentioned stages. In the first stage the literature studies and process analysis is employed to identify the main phases and processes of coal mining production and to assign environmental costs to selected process. In the second stage the case studies analysis is conducted on the basis of literature review. And in the third stage the environmental costs in coal mining production in Vietnam are presented in the statistical perspective and main conclusions about their determinants are formulated.

Coal mining has a very important meaning in the industrialization and modernization of Vietnam. However, the lack of master plan exploitation, regardless of the environmental landscape, has changed natural resources such as the gradual loss of cultivated land, the reduction of forest areas causing water pollution, including surface water, Groundwater and marine pollution also affect biological resources and public health in Vietnam today.

Through learning about the production and mining activities of coal mines in Quang Ninh Province - Vietnam, we found that the current coal mines do not really see the importance of environmental pollution in the coal mining process as well as pay attention to environmental costs.

We have used the documentary research method to study scientific topics and reports on environmental costs, coal production and mining. This method is also used to study legal documents, coal mining management documents for later analysis.

We have collected the necessary information related to environmental costs in coal production and mining at 41 coal mining units in Quang Ninh province. The main method of information collection used is the direct interview technique combined with copying documents. Interview questions:

(1) What are the environmental costs of mining production in theory and practice in a lifecycle of mining enterprises?

(2) What are the key determinants of environmental costs of mining production in a lifecycle of the mining enterprise?

We have used a number of statistical analysis methods such as descriptive statistics, comparison methods,... to analyze and evaluate the impact of environmental costs on production and mining enterprises coal in Viet Nam today. Since then, it is possible to make a graph of coal mining over a number of years; can determine the production cost of coal mining over the years; summing up the collection of environmental protection charges in coal mining over the years; calculating the rate of contribution to environmental protection tax revenue over the years.

\section{Results and discussion}

\subsection{Theoretical approach to environmental costs in the lifecycle of the coal mining firms}

The lifecycle of a mine - which is the integral part of the mining enterprise - includes three main stages: (i) starting up, (ii) exploitation and (iii) liquidation.

In each stage the environment is exposed to the negative influence of mining production and this influence could be limited through appropriate management approach. Nevertheless, it usually requires additional time and financial inputs, so naturally the mining firms not always are interested in such activities that in practice means also implementing the rules of sustainable development.

In fact, the catalogue of environmental costs in coal mining production is quite large and varied. The real level and the range of obligatory cost burden depends on two circumstances: (i) legal system and (ii) sustainability of a mining enterprise. The legal system - characterizing each country - defines the environmental framework for mining production and its completeness, interdisciplinary and perspectives directly influences on the scale of environmental protection implemented by mining firms. Nevertheless, adherence to the rules of law is not the only environmental duty in the extractive industry, especially when the legal system is imperfect and does not regulate all aspects and activities of mining production. The extractive industries have to be aware of the environmental risks they cause and responsibly prevent their generation and their consequences. It is this next step in thinking about environmental protection which separates normal and legal activities from sustainable activities (Ranängen \& Åsa, 2017; Bijańska \& Wodarski, 2014).

But it is worth emphasizing, that the financial costs of being sustainable and responsible in mining production are really very high, even if these are only in the legal scale, so the mining firms often avoid environmental costs and in this way they become unstainable and irresponsible. In the next two paragraphs we present the analysis of environmental costs in different stages of the mine lifecycle using case study methodology. 


\subsection{International case studies of environmental costs in mining firms}

In the stage of planning the mine and selecting its localization the environmental aspects become a subject of difficult discussions between the investors and local or regional communities which could delay the startup or even disable it. Therefore in this stage the proper preparation and gaining professional environmental knowledge is worth every effort and considering the environmental costs to convince the decision makers to agree to mining production. Furthermore, at this stage the cost of expert negotiations should be calculated and paid (Delgado \& Romero, 2016). It is quite an important issue, because in practice the vote of the local communities could effectively stop the starting up of a new mine, even when the mining project has met the necessary legal requirements and obtained the required environmental permits to be operational, as for example in Southern Chile in a case of coal mining initiative called Mina Invierno (Bustos et al., 2015). A similar situation took place in Ecuador where local communities and miners obtained the claim to improve working and living conditions and reduce the social and environmental problems associated with gold mining located in Chinapintza district (Sánchez-Vázquez, 2016; Maheshi et al., 2015).

During the exploitation stage the mining firms could invest in environmental protection or they could pay fines for environmental pollution and destroy their image and market value, but according to the research conducted in Colombia (Mining District of the Department of El Cesar) the first way is better, most effective and most efficient, because it allows for cost optimization. Results of research undertaken show that environmental externalities could be efficiently optimized and lowered than ex-post environmental fines, even if they are varied, changeable in time and quite high. In Vietnam, environmental costs fluctuate around 10,000 VND per ton of exploitation.

At the starting up stage of a coal mine and planning the mining activities, the key factors determining their success are: i) the temporal nature of mining operations; ii) spatial dimensions of mining operations; iii) irreversible changes that create post-mining landscapes; iv) social dimensions of mining impacts and corporate responsibility; v) cumulative dimensions of impacts; and vi) a need to integrate methods from a range of disciplines (Lechner et al., 2017). Forecasting all environmental and social costs including the above-mentioned aspects allows to estimate the efficiency of mining production in advance and intentionally influence their level without of a threat of unexpected financial consequences.

But in some cases the legal environmental regulations could cause the lack of economic efficiency at the exploitation stage and even lead to worsening the environment conditions. In Nevada in the United States of America, the introduction of a sophisticated regulatory regime for the gold coal mines belonging to the transnational mining corporations resulted in a dramatic decrease of their financial profits and caused development of the small scale ore mines and the artisanal ore mining sites as well moving the gold mining production to less developed regions where the legal regulations were less restrictive and the level of mercury emissions (accompanying the ore excavation) was not limited. Finally, globally, the negative influence of mining production on the environment went up, so the problem of extractive industries should be considered not only on regional or national scales but the global perspective should be also taken into consideration (Gulley, 2017).

Due to the greater experience and resources' potential the large mining firms are better prepared to implement environmental cost management and implementation. Small and medium enterprises focus on ad-hoc issues but they have already recognized the need to strengthen their environmental and social policies (Wirth et al., 2016).

At the liquidation stage the environmental threats and costs are especially visible, felt and harmful in the case of nuclear resources because of radioactive waste and the necessity of its appropriate storage. This problem nowadays - in the face of growing demand for nuclear energy - complicates life conditions in several African countries where existing uraniferous waste threatens scarce water resources and the health of local communities. Their unfavorable influence on the environment will last for hundreds of years. Meanwhile, resigning of excavation, in this case means loss of financial maintenance for many regions and communities because the share of the value of uranium production in African GDP exceeds 12\% (Winde et al., 2017; Matshusa \& Makgae, 2017).

With reference to the above, many studies pay attention to necessity of including the reclamation costs not only in the last stage of the mine lifecycle but before the decision of starting it up. The environmental costs in the stage of liquidation are quite high and of long-term character and they have serious impact on the total return of investment in the mining firms. They significantly extend the payback period and decrease the rate of return (Espinoza \& Morris, 2017).

The holistic research on financial costs of environmental and social impact of mining shows that the level of costs per ton in a case of open-pit coal mining in the whole lifecycle exceeds the unit price of this resource. These costs are higher after taking into consideration the health impact and climate change on a global scale (Cardoso, 2015).

\subsection{Environmental costs in Vietnam coal mining}

Coal mining is a industry in Vietnam and hard coal is the key energy resource in Vietnam's energy balance. Nevertheless, in the last 10 years, this sector is treated as a declining one which is reflected in decreased financial 
efficiency and in reduced demand. As a result, employment and production has been constantly decreasing.

Figure 1: Coal mining chart

Unit: thousand dong/ton

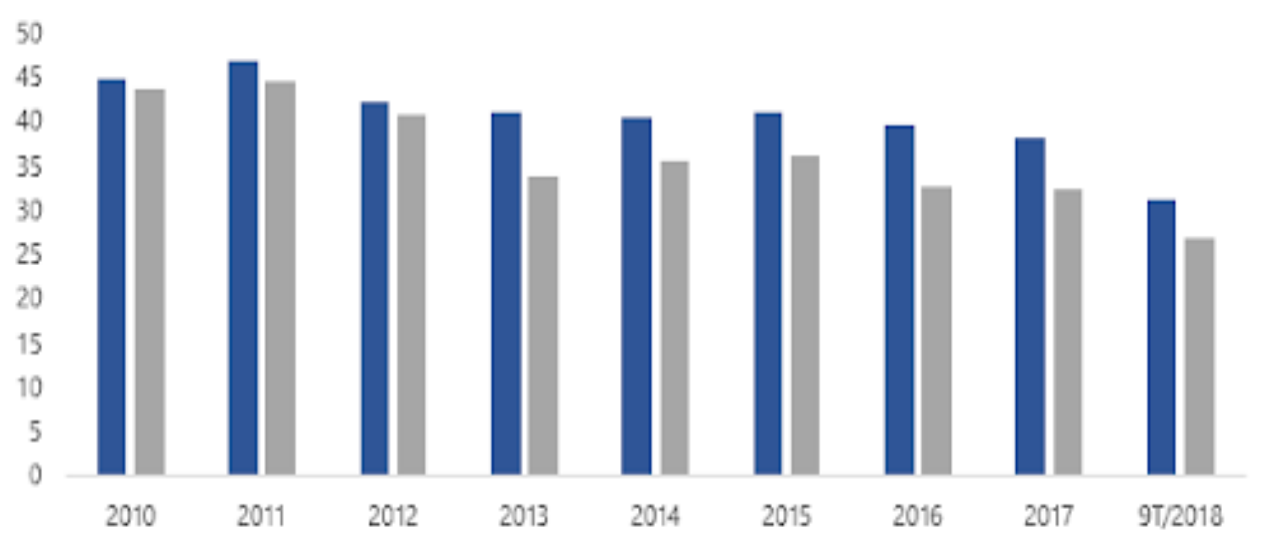

The environmental costs in Vietnam coal mining include three kinds of costs of (i) liquidation of coal mines and mining damages, (ii) environmental fees, and (iii) reclamation costs. The structure of these costs in recent years is presented in Figure 2.

Figure 2: Structure of environmental costs in Vietnam coal mining (average of years 2014-2020)

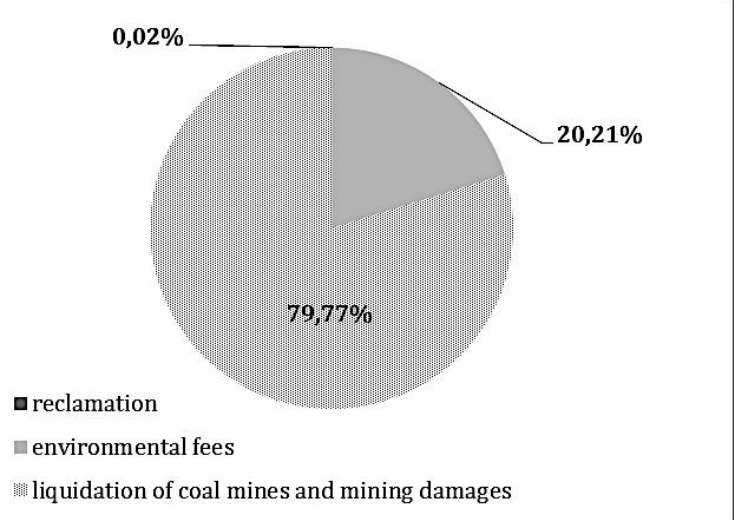

According to Figure 2, the costs of liquidation of coal mines and mining damages are the biggest financial burden for Vietnam coal mining firms which is the result of systematic reduction of coal mines and the on-going mining waste recovery. Vietnam coal mines were and are located mostly in Quang Ninh province which is strongly urbanized and equipped with a dense network of roads and highways and as a result it is the region strongly exposed to the negative influence of underground mining production.

The environmental fees are the second important group of costs. They are connected with water pollution, generating rock mass and extractive waste, and dust and gas emission (Brodny \& Tutak, 2016). Additionally, the reduction in coal production is not clearly reflected in the reduction of the pollution of ecosystems. The limitation of extraction has not caused the decrease of environmental costs per ton of production. 
Figure 3: Environmental protection tax revenues over the years (billions dong)

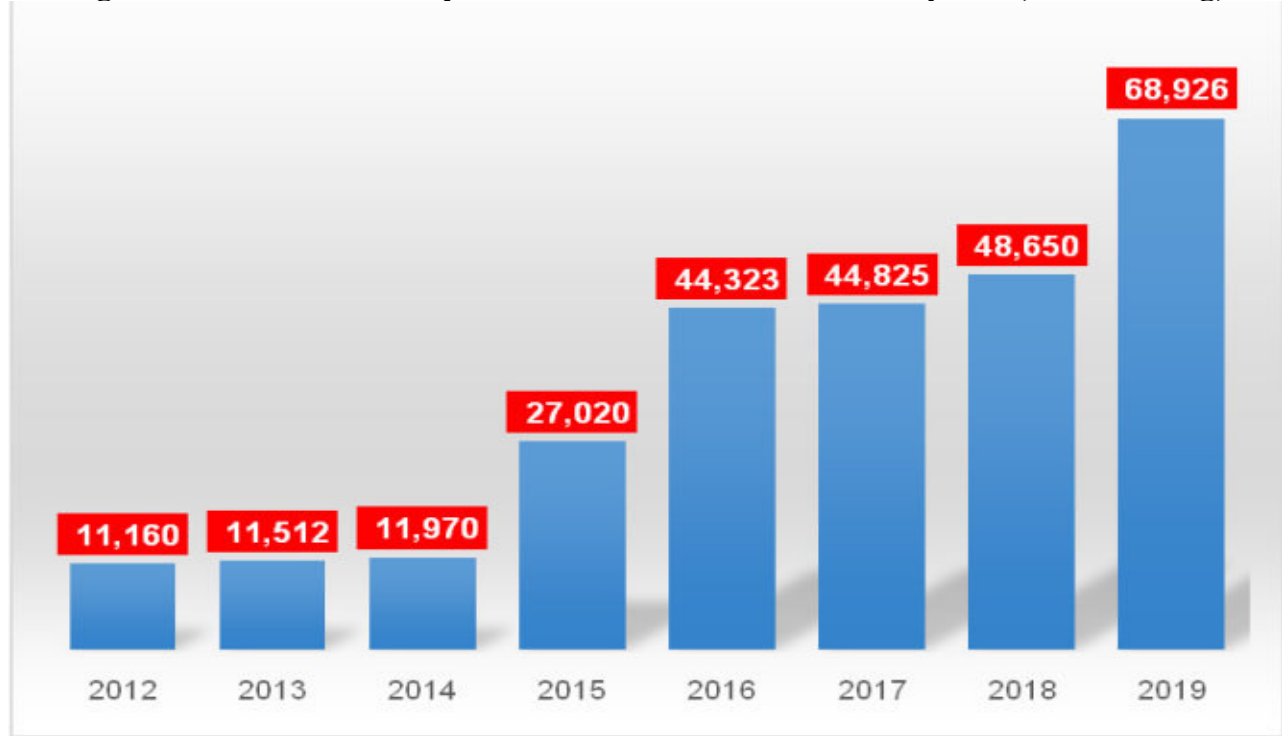

The policy of higher and higher tariffs - up to $16 \%$ of coal price is one of the factors driving up coal prices (Figure 4). These policies not only affect the financial balance and the reproduction process of the coal industry, but also indirectly impact the increased loss of resources due to difficult exploitation conditions and high costs.

Figure 4: Coal production cost, 2001-2030

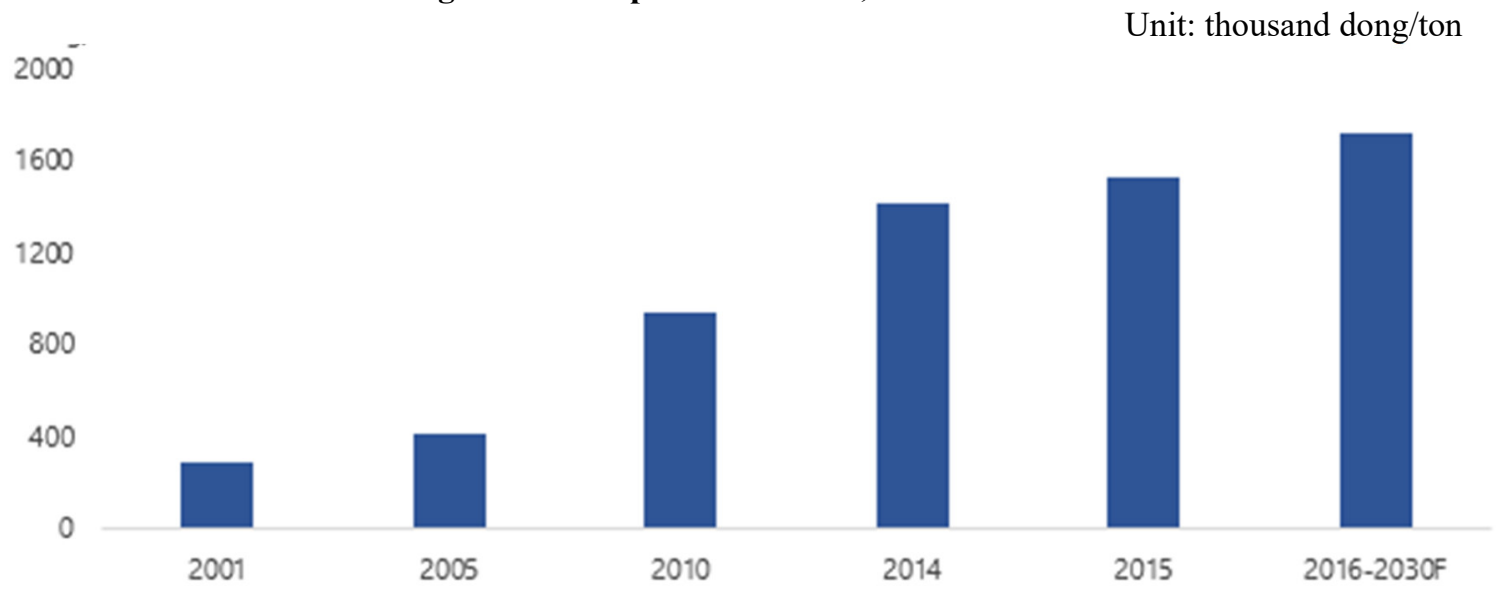

As follows: The current environmental protection fee for coal exploitation in Vietnam is from VND 6,000 Vietnam Dong / ton - 10,000 Vietnam dong/ton.

Royalties increased from $1 \%$ to $5 \%$, to $7 \%$ and $10 \%$ (for underground coal) and from $2 \%$ to $7 \%$ to $9 \%$ (from February 1, 2014 according to Resolution No. 712/2013 of National Assembly Standing Committee) and from July 1, 2016 increased to 12\% (Resolution No. 1084/2015 of National Assembly Standing Committee).

In addition to the aforementioned natural resources tax, the enterprise must pay a royalty of $2 \%$ for coal; Advance payment for new projects is $4 \%$ of the same price as the royalty calculation price (Decree No. 203/2013 of government dated November 28, 2013). 
Figure 5: Contribution rate to environmental protection tax revenue)

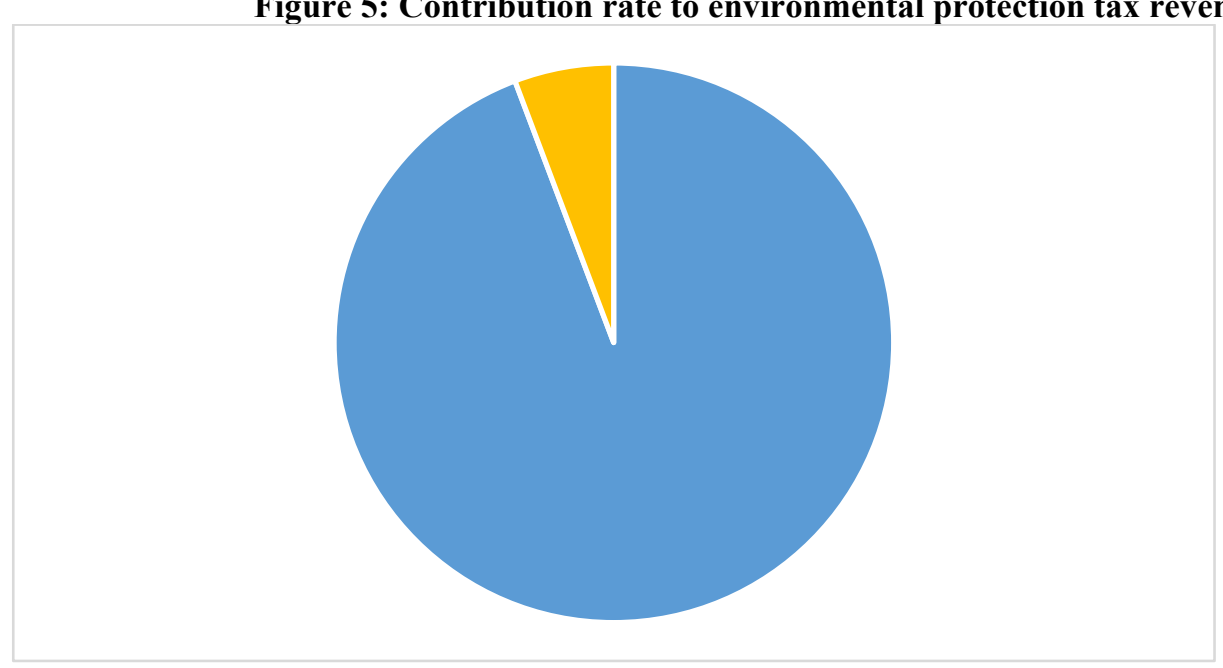

Coal: $1.9 \%$

Petroleum: $97.9 \%$

According to the statistics of countries in the region, Vietnam is a country with a high royalty tax bracket in the world, if the calculation of the royalty fee is too high compared to other countries: Australia royalty: 7 to $10 \%$ income; NSW: 7\% open space, $6 \%$ pit and 5\% deep exploitation $>400 \mathrm{~m}$; Russia anthracite: 47 to 57 rubles/ton, brown coal 11 rubles/ton, other coal 24 rubles /ton (about 3 to 6\%); China: 2 to $8 \mathrm{RMB} /$ ton and 0.5 to $4 \%$ of income (about 5 to $10 \%$ ); India: (55R/ton $+5 \%(\mathrm{P})$ profit to $130 \mathrm{R} / \mathrm{t}+5 \%(\mathrm{P}))$; Indonesia Royalty: 3 to $7 \%$ of income; Philippines royalty: 5\%; South Africa Royalty: 0.5 to $7 \%$.

Policies on taxes and fees for minerals are on the rise in both aspects: the number of taxes, fees and each type of tax and fee. Increasing taxes and fees together with increasingly difficult and complicated mining conditions have made the exploitation cost increase, resulting in a decrease in the business efficiency of the mining firms, causing them to have to manage in reality. Currently, the solutions are detrimental to full exploitation of resources and environmental protection to remain profitable.

\section{Conclusion}

The environmental costs in coal mining production are varied and high and in each stage of the lifecycle they comprise a significant burden for the mining firms. Therefore the mining firms try to avoid the responsibility for environmental pollution and covering the environmental costs. It is especially visible in less developed countries where the legal protection is at a lower level and corrupt practices are more frequent. Nevertheless, even in civilized and economically developed regions the activity of extractive industries is controversial and mining firms are not welcomed.

To improve the image of the coal mining firms and to force them to be more environmental responsible and friendly it is necessary to:

(i) Ensure complete legal regulations for mining activity at the national, regional and local scales;

(ii) Ensure honest and constant communication between the mining firms and regional communities in each stage of the mining lifecycles;

(iii) Predict, plan and manage the environmental costs in the long-term perspective;

(iv) Seek methods of limiting the negative influence of extractive industries on the environment;

(v) Guarantee the sources of funding for covering not only the current environmental costs but also the costs of post-liquidation stage such as the costs of liquidation mines and mining damages and the reclamation costs (for example in the form of economic insurance, public obligatory fund, co-financing with regional and local government units or gaining finance from environmental programs or projects).

Further research on environmental costs pertaining to the mining industries should focus on examining their level and determinants as well as on the methods of forecasting them. In terms of the importance of legal regulations a comparative analysis on an international scale could be also taken as a separate research plot. Additional important research directions lie in the gaining and optimization of financial structures for mines liquidation.

\section{References}

Bąk, P. (2007). Characteristic of the capital gaining sources and financing the activity of coal mine enterprises. 
Part 1:Sources of the own capital. Gospodarka Surowcami Mineralnymi-Mineral Resouces Management, 23(1), 93-108.

Bijańska, J., \& Wodarski, K. (2014). Risk management in the planning of development projects in the industrial firms. Metalurgija, 53(2), 276-278.

Brzostek K., \& Michna, A. (2016). Empirical research on the relationship between knowledge management, market orientation and small and medium-sized firms performance - selected preliminary results. 4th International Conference on Innovation Management, Entrepreneurship and Corporate Sustainability (IMECS 2016). Edited by: Lukes, M; Misar, J; Mares, J., 66-76.

Brodny, J., \& Tutak, M. (2016). Analysis of gases emitted into the atmosphere during an endogenous fire. [In:] 16th International Multidisciplinary Scientific GeoConference. SGEM 2016, SGEM Vienna GREEN Extended Scientific Sessions. Wienna. Conference Proceedings. Book 4, Vol. 3. Sofia: STEF92 Technology, 75-82.

Bustos, B., Folchi, M., \& Fragkou, M. (2016). Coal mining on pastureland in Southern Chile; challenging recognition and participation as guarantees for environmental justice. Geoforum, In Press, Corrected Proof, Available online 4 February 2016.

Caputa, W. (2015). Pomiar kapitalu klienta w kontekście kreowania wartości przedsiębiorstwa.

Cardoso, C. (2015). Behind the life cycle of coal: Socio-environmental liabilities of coal mining in Cesar, Colombia. Ecological Economics, 120, 71-82. DOI: http://dx.doi.org/10.1016/j.ecolecon.2015.10.004.

Delgado, A., \& Romero, I. (2016). Environmental conflict analysis using an integrated grey clustering and entropyweight method: A case study of a mining project in Peru. Environmental Modelling \& Software, 77, 108-121. DOI: http://dx.doi.org/10.1016/j.envsoft.2015.12.011.

Espinoza R. D., \& Morris J. W. F, (2017). Towards sustainable mining (part II): Accounting for mine reclamation and post reclamation care liabilities. Resources Policy, 52, 29-38. DOI: http://dx.doi.org/10.1016/j.resourpol.2017.01.010.

Fugiel, A., Burchart-Korol, D., Czaplicka-Kolarz, K., \& Smoliński, A. (2017). Environmental impact assessment of mining and quarrying sector in European countries. Journal of Cleaner Production, 143, 159-168.

Gorczyńska, A. (2011). The impact of the crisis on the course of cross-border consolidation processes.

Gulley, A. L., (2017).Valuing environmental impacts of mercury emissions from gold mining: Dollar per troy ounce estimates for twelve open-pit, small-scale, and artisanal mining sites. Resources Policy, 52, 266-272.

Lechner, A. M., McIntyre, N., Witt, K., Raymond, Ch., M., Arnold, S., Scott, M., \& Rifkin W., (2017). Challenges of integrated modelling in mining regions to address social, environmental and economic impacts. Environmental Modelling \& Software, 93, 268-281.

Maheshi, D., Van Passel, S., \& Van Acker, K. (2015c). Environmental and economic assessment of 'open waste dump' mining in Sri Lanka. Resources, Conservation and Recycling, 102, 67-79.

Maheshi, D., Van Passel, S., Vanderreydt, I. \& Van Acker, K. (2015a). Assessment of environmental and economic feasibility of Enhanced Landfill Mining. Waste Management, 45, 434-447.

Maheshi, D., Van Passel, S., Vanderreydt, I. \& Van Acker, K. (2015b). Environmental and economic performance of plasma gasification in Enhanced Landfill Mining. Waste Management, 45, 458-467.

Matshusa, K., \& Makgae, M. (2017). Prevention of future legacy sites in uranium mining and processing: The South African perspective. Ore Geology Reviews, 86, 70-78.

Michalak, A. (2016). The cost of capital in the effectiveness assessment of financial management in a company. Oeconomia Copernicana, 7 (2), 317 - 329.

Ranängen, H., \& Lindman, A. (2017). A path towards sustainability for the Nordic mining industry. Journal of Cleaner Production, 151, 43-52.

Sánchez-Vázquez, L., Espinosa-Quezada, M. G. \& Eguiguren-Riofrío, M. B., (2016). Golden reality" or the "reality of gold": Artisanal mining and socio-environmental conflict in Chinapintza, Ecuador. The Extractive Industries and Society, 3 (1), 124-128.

Stevens, J., \& Dixon K., (2017). Is a science-policy nexus void leading to restoration failure in global mining? Environmental Science \& Policy, 72, 52 - 54.

Szromek, A.R., Romaniuk, P., Krajewski-Siuda, K., Gericke, Ch.A., Szpak, A., \& Kaczmarek, K.(2011). Emigration preferences and plans among medical students in Poland. Human Resources for Health, 10, 8-12.

Winde F., Brugge D., Nidecker A., \& Ruegg U., (2017). Uranium from Africa - An overview on past and current mining activities: Re-appraising associated risks and chances in a global context. Journal of African Earth Sciences, 129, 759-778.

Wirth, H., Kulczycka, J., Hausner, J., \& Koński, M., (2016). Corporate Social Responsibility: Communication about social and environmental disclosure by large and small copper mining companies. Resources Policy, 49, 53-60. 